\title{
Do the stock returns of clean energy corporations respond to oil price shocks and policy uncertainty?
}

\author{
Xiaohui Zhao*
}

*Correspondence:
zhao.xiaohui@i.mbox.
nagoya-u.ac.jp
Graduate School
of Economics, Nagoya
University, Furo-cho,
Chikusa-ku, Nagoya-shi,
Aichi-ken 464-8601, Japan

*Correspondence: zhaoxiaohui@imbox. of Economics, Nagoya Chikusa-ku, Nagoya-shi, Aichi-ken 464-8601, Japan

\begin{abstract}
This paper investigates the effects of oil price shocks and policy uncertainty on the stock returns of clean energy companies. We use a structural vector autoregressive (VAR) model to separate demand and supply shocks in the global crude oil market from 2001 to 2018. We find that oil supply shocks and aggregated demand shocks have a positive effect on the returns of clean energy companies, while policy uncertainty shocks and oil-specific-demand shocks have a negative effect. The impacts of these shocks are shown to last relatively long. Moreover, the effects of oil shocks on the clean energy stock returns are amplified by adding policy uncertainty as an endogenously driven factor to the model. The impact of policy uncertainty is mainly transmitted through the uncertainty of inflation.
\end{abstract}

Keywords: Oil price shocks, Policy uncertainty, Clean energy companies, Stock market

\section{Introduction}

With the global pressure caused by climate change and air pollution, traditional energy users are considering the possibility of using clean energy alternatives such as solar, wind, and hydropower. The uncertainties in the oil market, such as unpredicted increases in oil prices, stress the need for energy substitution and may accelerate the energy transition. Although changes in the price of oil are often considered a crucial factor for the development of clean energy, there is no consensus among economists about the relation between the stock prices of clean energy and the prices of oil. Therefore, to shed light on the link between oil price and renewable energy stock price, a more detailed analysis is necessary.

Kilian (2009) argues that, historically, oil price shocks have mainly been driven by a combination of global aggregate demand shocks and precautionary demand shocks, rather than by oil supply shocks. The author attributes fluctuations in the real price of oil to three structural shocks in the oil market. Using structural vector autoregressive (VAR) decomposition of the real price of oil as proposed by Kilian (2009), Kang et al. (2017) investigated the effects of oil price shocks and economic policy uncertainty on the stock returns of oil and gas companies. They found that, on average, a demand-side

(c) The Author(s) 2020. This article is licensed under a Creative Commons Attribution 4.0 International License, which permits use, sharing, adaptation, distribution and reproduction in any medium or format, as long as you give appropriate credit to the original author(s) and the source, provide a link to the Creative Commons licence, and indicate if changes were made. The images or other third party material in this article are included in the article's Creative Commons licence, unless indicated otherwise in a credit line to the material. If material is not included in the article's Creative Commons licence and your intended use is not permitted by statutory regulation or exceeds the permitted use, you will need to obtain permission directly from the copyright holder. To view a copy of this licence, visit http://creativeco mmons.org/licenses/by/4.0/. 
oil shock has a positive effect on the returns of oil and gas companies, whereas shocks to policy uncertainty have a negative effect on stock returns. Using these two studies as a starting point, this paper extends the literature by examining the impact of four factors-oil supply shocks, aggregated demand shocks, oil-specific demand shocks, and policy uncertainty shocks-on the stock returns of clean energy companies. We employ a structural VAR model using monthly data from January 2001 to December 2018.

Among four factors affecting the stock returns of renewable energy companies, the first three (oil supply shocks, aggregated demand shocks, oil-specific demand shocks), are considered by Kilian (2009) to be the main factors affecting oil prices. They are also used by Kang et al. (2017) as the oil related factors affecting the stock returns of oil and gas companies. Since renewable energy is substitutable with oil, these three factors are considered to affect renewable energy stock returns as well. For example, some oil users who cannot afford high oil prices may increase the demand of renewable energy and decrease the demand of oil.

A large number of studies investigated the impact of the last factor, policy uncertainty, on stock market returns (Antonakakis et al. 2013; Kang and Ratti 2013; Liu and Zhang 2015). Among them, Kang et al. (2017) showed that policy uncertainty significantly affects the stock returns of oil and gas companies. For the renewable energy sector, policy supports the development of clean energy in its emerging stage through financial subsidies from government, investment tax credits, accelerated depreciation, transfer payments, and preferential tax policies. As such, policy uncertainty can be considered an important factor affecting renewable energy stock returns.

Our empirical study reveals the following results: (1) Oil supply shocks and aggregated demand shocks have a positive effects on the stock returns of clean energy companies, while policy uncertainty shocks and oil-specific demand shocks have a negative effect; (2) These shocks are shown to last relatively long; (3) The effects of oil shocks on clean energy stock returns are amplified by adding policy uncertainty as an endogenous factor; (4) The impact of policy uncertainty is mainly transmitted by the uncertainty of inflation.

Our first result indicates that a decrease in oil supply leads to an increase in renewable energy stock returns, implies that there exists a substitution effect between oil and renewable energy. Renewable energy companies can profit more when the oil supply decreases because oil users increase the demand for renewable energy. Furthermore, an increase in oil-specific demand leads to a decrease in renewable energy stock return, which implies that there exists no substitution effect between oil and renewable energy for the oil-specific users. Renewable energy companies lose more when the oil-specific demand increases because such oil-specific users do not increase the demand for renewable energy. In addition, aggregated demand increases lead to increases in renewable energy stock returns, which implies that aggregated demand makes energy-related companies profit no matter what kinds of energy. Finally, an increase in policy uncertainty leads to a decrease in renewable energy stock returns, which implies that there is an uncertainty effect in the renewable energy segment as well. Policy uncertainty is an important factor affecting renewable energy stock returns.

Our second result shows that, from a long-term perspective, oil supply shocks explain $14 \%$ of the variation in the US real stock returns of clean energy companies, aggregate demand shocks explain 11\%, oil-specific demand shocks explain 18\%, and the 
uncertainty shocks account for $15 \%$. The four types of shocks explain $59 \%$ of the variation, revealing they are essential determinants of the renewable energy stock returns.

Our third result reveals that policy uncertainty is negatively affected by an increase in aggregate demand, and that it is significantly and negatively affected by a decrease in oil supply. Meanwhile, an increase in oil-specific demand has a positive effect on policy uncertainty. Through these three channels, the policy uncertainty shock is amplified to have a greater effect on the renewable energy stock returns. Regarding the fourth result, our analysis shows that, among the four uncertainty components, the uncertainty in the inflation forecast has the most significantly negative impact on renewable energy stock returns.

This study is the first to analyze the joint effect of these four factors on renewable energy stock returns using a structural VAR model. While the study by Kang et al. (2017) is similar to ours, our approach is different in that we analyze renewable energy stock returns, instead of oil and gas stock returns. Furthermore, several studies investigated the impact of oil-specific demand on renewable energy (Bondia et al. 2016; Dutta et al. 2018; Henriques and Sadorsky, 2008; Inchauspe et al. 2015; Kumar et al. 2012; Managi and Okimoto 2013; Reboredo et al. 2017; Sadorsky 2012). However, there are no studies investigating the impact of oil supply and aggregate demand on the renewable energy stock market. This study contributes to this literature by using a structural VAR model to provide new evidence regarding the impact of oil supply and aggregate demand on renewable energy stock returns.

Several studies also investigated the impact of uncertainty on oil price (Aloui et al. 2016; Antonakakis et al. 2014; Degiannakis et al. 2018; Kang and Ratti, 2013). In addition, the impact of uncertainty on renewable energy has also got some attentions (Ferrer et al. 2018; Ji et al. 2018; Lundgren et al. 2018). For example, Lundgren et al. (2018) found spillover effects from American and European economic policy uncertainty on both returns and volatilities of several clean energy indices. Ji et al. (2018) used a time-varying copula-based CoVaR model to estimate the impact of economic policy uncertainty on the global renewable energy index. Our study adds to the literature by specifically analyzing the impact over a 2-year period and by separating the different sources of policy uncertainty to make the analysis more comprehensive in a structural VAR model.

The remainder of this paper is structured as follows. "Literature review" section reviews the literature on the interaction between the stock returns of clean energy corporations, oil shocks, and policy uncertainty. "Data, methodology and hypotheses" section describes the dataset and the methodology. "Results" section presents the empirical analysis, in which we estimate the impact of both structural oil price shocks and uncertainty on the real stock returns of renewable energy companies. Finally, "Conclusion" section presents the conclusion of the paper.

\section{Literature review}

The renewable energy sector has been investigated from various perspectives. A growing body of literature has focused on the financial performance of clean energy companies in this decade. Many economic indicators related to the development of renewable energy have been examined from a macroeconomic perspective. These include oil prices, technology stocks, interest rates, aggregated stocks, and so on. 
A first group of scholars focus on the level and return of renewable energy stocks. Henriques and Sadorsky (2008) analyzed the relationship between oil prices and alternative clean energy stocks, noting that renewable energy companies operate like high technology companies. ${ }^{1}$ Using the Granger causality test and LA-VAR model, they found that technology stock prices affect US clean energy stock prices more significantly than oil prices. Kumar et al. (2012) employed the same method and extended this topic to the global renewable energy stock market, confirming similar influential abilities of oil and technology. Managi and Okimoto (2013) further expanded the study by Henriques and Sadorsky (2008) by considering the structural breaks. They found a positive impact of oil price on renewable energy stocks returns, which become more significant after 2008. Again based on the study by Managi and Okimoto (2013), Bondia et al. (2016) employed the cointegration method with structural breaks to study the long-term relationship between the stock prices of clean energy companies, oil prices, technology stocks, and interest rates. They found significant short-term causal relationships between macroeconomic variables and clean energy stock prices.

Aside from the VAR model, novel methods are increasingly being used in research on renewable energy stock markets. For example, Inchauspe et al. (2015) used a statespace approach to examine the time-varying impact of the aggregated stock market, technology, and oil prices on renewable energy companies. They found that, in the sample period, the impacts of aggregated stock market and technology were always significant, whereas the impact of oil prices were significantly lower before 2007 and gradually became more influential.

A second group of scholars focus on the volatility of renewable energy stocks and risk spillover. Sadorsky (2012) analyzed the volatility dynamics of clean energy stocks and other financial variables. He confirmed that the correlation level of oil prices is significant and emphasized that technology stock prices have a higher correlation level with US clean energy stock prices. Aware of the importance of oil on the variances of clean energy stocks, Dutta (2017) tested the impact of oil fluctuation on the realized volatility of clean energy stocks. This study found that oil uncertainty can provide some additional information that partially explains the volatility of clean energy stocks.

Reboredo (2015) investigated systemic risk and dependence between oil prices and clean energy stock returns. Focusing on the tail dependence, he found that oil prices significantly contributed to about $30 \%$ of the tail risk of renewable energy companies. A later study by Reboredo et al. (2017) extended the analysis on dependence and causality between oil prices and renewable energy stocks prices by considering different times scales. The authors documented stronger dependence in the long run during 2008-2012 and mixed causality relationships for these two energy markets. This result is also supported by Paiva et al. (2018) within a detrended cross-correlation analysis framework. Using a multivariate vine-copula dependence method, Reboredo and Ugolini (2018) extended the analysis about clean energy dependence even further and highlighted the impact of the price of oil and electricity on the clean energy stocks prices, comparing them to gas and coal prices.

${ }^{1}$ We also add the same technology factor into our model, and the main findings are robust. To save space, results are not reported, but are available upon request. 
A third group of scholars analyze the uncertainty of renewable energy stocks. After Dutta (2017) study scrutinizing the impact of oil uncertainty, scholars analyzed additional kinds of uncertainty. Lundgren et al. (2018) built a connectedness network among renewable energy stocks and uncertainty caused by the financial market and policy. They reported the importance of uncertainty regarding the return and volatility of clean energy stocks. Ferrer et al. (2018) went a step further to examine the connectedness of renewable energy stocks using a dynamic time and frequency analysis method. They documented a decoupling of two kinds of energy, and found that renewable energy is closer to a technology indicator when controlling for the impact of financial factors and the uncertainty of these financial factors. Ji et al. (2018) compared the impact of uncertainty from the financial market, oil market, and economic policy on the energy stock market. Using the CoVaR method to examine risk spillover and tail dependence, they concluded that policy uncertainty had a weaker effect than the other two factors. They also found that policy uncertainty was more important in the context of renewable energy stocks than for conventional energy stocks.

\section{Data, methodology and hypotheses}

\subsection{Data description}

We use monthly data series over the period from January 2001 to December 2018, as the data on the clean energy index is only available starting in January 2001. The stock returns of the clean energy industry $\left(\Delta e c o_{t}\right)$ is obtained using the first difference of the $\log$ index entitled WilderHill Clean Energy Index. This is a popular index displaying the development of renewable energy in US stock markets. Like Kang et al. (2017), we also use the stock returns of the oil and gas industry $\left(\Delta \operatorname{og}_{t}\right)$ and of the overall stock market in the US $\left(\Delta \mathrm{sp}_{t}\right)$ to compare the difference of renewable energy segments with conventional energy segments and the whole market. Data on the oil and gas industry are obtained from the Fama-French Data Library, and the S\&P 500 index is from the Fred Economic data. All stock returns have subtracted the impact of the consumer price index (CPI) inflation rate in the US

Following Kilian (2009), we use three series to display the underlying causes of oil price changes. Regarding supply, the supply shock is represented by the percent change in the global crude oil production $\left(\Delta \operatorname{prod}_{t}\right)$, calculated by difference in log of world crude oil production in a month. Demand side has two components: aggregated demand shock and oil-specific demand shock. Aggregated demand shock is measured by the global real economic activity index $\left(\mathrm{rea}_{t}\right)$. Kilian (2009) constructed this index by using an equalweighted index of the percent growth rates obtained from single voyage bulk dry cargo ocean shipping freight rates. Dry cargo ocean shipping freight rates show the demand of shipping services, which can indirectly indicate the demand of global commodity and global economy activity. The oil-specific demand shock reflecting the oil consumers' precaution is represented by using the demeaned real price of oil $\left(\mathrm{rpo}_{t}\right)$. The real oil price is the US refiner acquisition cost of imported crude oil deflated by the US CPI. The crude oil price and production data are obtained from the US Department of Energy, and the global real economic activity index is obtained from Kilian's Data Library.

Baker et al. (2016) constructed the economic policy uncertainty index $\left(\mathrm{pu}_{t}\right)$ by using a weighted average method to incorporate the uncertainty information from four 

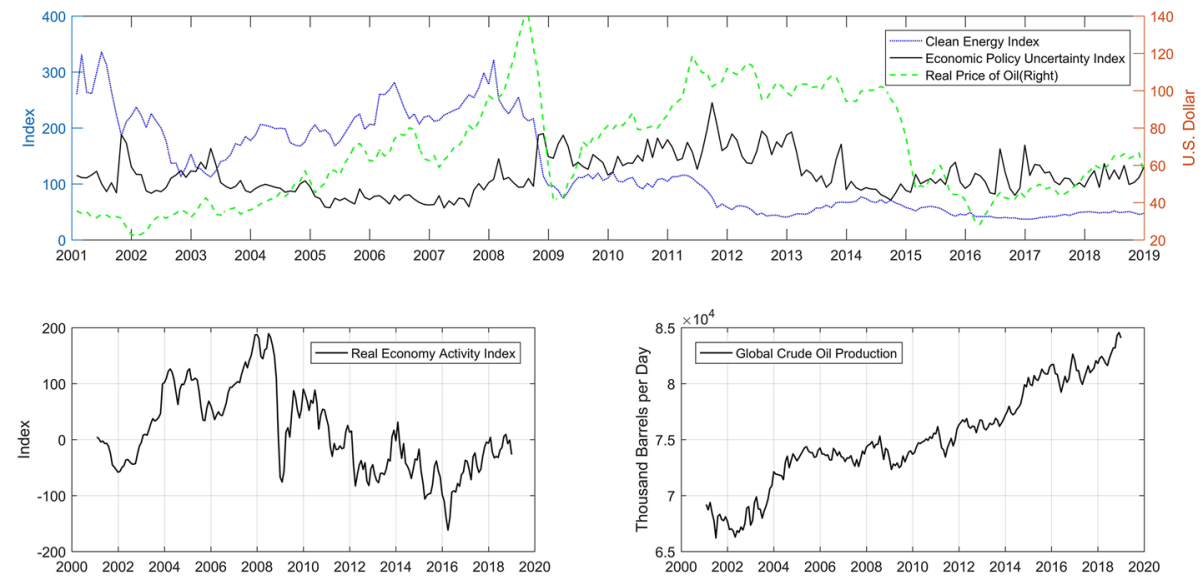

Fig. 1 Time trends of main variables, 2001:01-2018:12. Notes: Subplot A shows monthly data of real oil prices, economic policy uncertainty index and the real stock return of oil and gas industry. Subplot B shows monthly data of real economy activity index, constructed by Kilian using the single voyage bulk dry cargo ocean shipping freight rates. Subplot $C$ shows monthly data of the world crude oil production

channels. Specifically, the news-based policy uncertainty quantified from the newspaper coverage of the policy-related economic uncertainty takes $1 / 2$ of the weight. The tax legislation expiration uncertainty, represented by the number of federal tax code provisions set to expire in the future years, and the economic forecast interquartile ranges about US CPI and about federal/state/local government expenditures occupy another half of the weight in the index (1/6 each).

Figure 1 displays the main variables we used in this study, showing the historical evolution of these time-series data between January 2001 and December 2018. We can see that the oil production is always in an upward trend with diminishing changes. Also, real oil prices are relatively stable in the first half of the sample period while experiencing some dramatic ups and downs in last 10 years. The ups and downs of the economic activity index depicts the global economic cycle in the past 18 years, and the economic policy uncertainty index reacts to the rise after the well-known events related to the oil market, such as 2003 Iraq War, 2013 Arab Spring. The renewable energy stock index is also relatively stable before the financial crisis. After the crisis, it once again falls into the lower stable zone.

\subsection{Methodology}

Using a structural VAR model, Kilian (2009) decomposed the real price of oil fluctuations into three structural shocks in the oil market and examined the endogenous relationships among these shocks. Other studies added more variables after three shocks to investigate the impacts of different oil shocks on such as GDP, CPI, stock returns and policy uncertainty (Kang and Ratt 2013; Kilian and Park 2009; Kim and Vera 2018).

In this study, we follow Kang et al. (2017) in estimating the impacts of the oil price shocks and of US economic policy uncertainty on the stock returns of clean energy companies, using a structural VAR model with a 24 lag: 


$$
A_{0} y_{t}=c_{0}+\sum_{i=1}^{24} A_{i} y_{t-i}+\varepsilon_{t} \#
$$

In this model, $y_{t}^{\prime}=\left(\Delta \operatorname{prod}_{t}, \mathrm{rea}_{t}, \mathrm{rpo}_{t}, \mathrm{pu}_{t}, \Delta \mathrm{eco}_{t}\right)$ is a $5 \times 1$ vector of endogenous variables, $A_{0}$ denotes a $5 \times 5$ contemporaneous coefficient matrix, $c_{0}$ represents a $5 \times 1$ vector of constant terms, $A_{i}$ refers to $5 \times 5$ lagged coefficient matrices, and $\varepsilon_{t}$ is a $5 \times 1$ vector of structural disturbances with no serial and mutual correlation. Following Kilian (2009), we used a 2-year lag length of SVAR to acquire the potentially longdelayed effects of oil price shocks and uncertainty on the renewable energy sector.

Kilian (2009) assumes that $A_{0}^{-1}$ is a lower triangle coefficient matrix. This identifying restriction introduces a recursively identified structural VAR model as $e_{t}=A_{0}^{-1} \varepsilon_{t}$ , where $e_{t}$ represents errors from the reduced-form VAR model. This lower triangle assumption implies that oil production affects other variables within a given month, while the opposite impacts have a lag to wait the adjustment of the production plan. It is a reasonable assumption because oil supply shocks are only affected by exogenous events. Similarly, due to the sluggishness of aggregate economic reaction, real economic activity does not respond to the fluctuation of the real price of oil within a given month.

Kilian and Vega (2011) argue that oil prices are predetermined with respect to US macroeconomic aggregates within the month. Therefore, economic policy uncertainty is affected by oil shocks within a given month, and the impact of policy uncertainty on oil shocks has a lag. The real stock return ordered at the final position implies that the direct effects of oil supply and demand shocks on the stock returns would be amplified by the endogenous policy uncertainty responses. This also reveals the amplification degree of the endogenous policy uncertainty in response to oil shocks. Considering the economic policy uncertainty endogenously captures its important role in the transmission of the three structural oil price shocks in the US, the international stock markets, and oil and gas stocks (Kang and Ratti 2013; Kang et al. 2017).

\subsection{Hypotheses}

In this study, we focus on the impacts of four factors affecting the development of the renewable energy industry. Based on the data available, we use the stock index of renewable energy companies as a proxy for renewable energy development. To scrutinize these impacts clearly, we propose four hypotheses that have not yet been tested in the renewable energy sector.

Hypothesis 1. A decrease in oil supply increases the returns of renewable energy stocks

Unanticipated decreases in oil production affect almost any oil consumer's activities on the supply side. As renewable energy is one alternative that can replace oil in some situations, the substitution effect can explain the relationship between renewable energy and oil. Due to the substitution effect, some oil users that cannot afford high oil prices transfer to renewable energy. This energy transfer can increase the demand for renewable energy, boost the renewable energy industry, and increase the profits of renewable energy companies. Therefore, we assume that an oil supply shock increases 
the return of renewable energy stocks. It is worth mentioning that, in Kilian's (2009) analysis, this supply shock is deemed weaker than other demand-side shocks. However, we believe that the substitution effect makes this supply shock just as important as other shocks.

Hypothesis 2. Aggregate economic activity increases the returns of renewable energy stocks

Unanticipated economic booms cause an increase in the energy demand of any energy consumer, due to a positive forecast about future economic trends. Due to the substitution effect, some traditional energy consumers will make trade-offs between continuing to using oil and turning to renewable energy. We believe this transition to environmentally-friendly energy is more easily achieved during periods of economic prosperity. Therefore, economic prosperity is good news for the renewable energy industry and can increase the return of renewable energy stocks.

Hypothesis 3. The precautionary demand of crude oil decreases the returns of renewable energy stocks

The precautionary demand of crude oil is a factor that can provoke changes in oil price, after identified the reasons mentioned above. Oil consumers increase their oil demand not because of increased oil demand in their product process, but because of their anxiety about oil supply shortfalls in the future. It implies that these oil consumers rely on oil heavily and cannot transition to renewable energy due the increase in energy cost. Therefore, if there is no substitution effect happening in this kind of oil shock, the stocks of oil-related companies would benefit while renewable energy stocks would experience decreased returns.

Hypothesis 4. Policy uncertainty decreases the returns of renewable energy stocks and amplifies the impacts of oil shocks

Unanticipated economic policy uncertainty is indicative of an unstable policy environment. Changes in or the elimination of supporting policies are disastrous for the renewable energy industry. Therefore, in periods of high economic policy uncertainty, the sensitivities of renewable energy companies make stocks prices decrease. And oil price shocks, as predetermined economic factors, affect the changes of policy uncertainty.

\section{Results}

\subsection{The effects of structural shocks on the real stock returns of renewable energy companies}

This subsection investigates the main results regarding the effects of structural shocks on the US real stock returns of clean energy companies. Figure 2 indicates the cumulative impulse responses of the real clean energy stock returns in a 24-month forecasting horizon to the four structural shocks. One and two standard error bands are constructed using a recursive-design wild bootstrap (Gonçalves and Kilian 2004). The estimates focus on structural shocks in oil supply, aggregated demand, oil-specific demand, and economic policy uncertainty. The real stock return of the clean energy industry is the fifth variable in the VAR model to represent other shocks from the clean energy industry (Fig. 2). Following Kilian's (2009) SVAR model, the oil supply shock has been normalized to represent a negative one standard deviation shock, whereas the aggregate demand shock and oil-specific demand shock are normalized as positive shocks. Thus, all three 

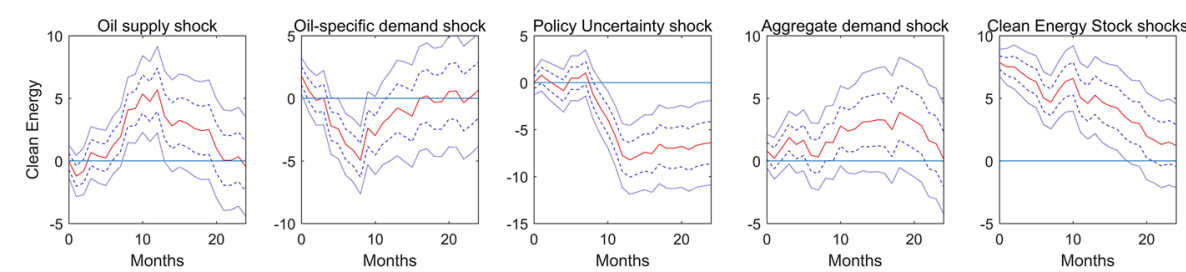

Fig. 2 Responses of clean energy industry returns to one and two standard deviation structural shocks: 2001:01-2018:12. Notes: The figure shows the impulse response functions to one and two standard deviation structural shock, the order of SVAR model is oil supply shocks, aggregated demand shocks, oil specific demand shocks, economic policy uncertainty index and the real stock returns of the clean industry described in the text. Point estimates are reported with one- and two-standard error bands constructed using a recursive-design wild bootstrap

shocks tend to increase the real price of oil. Like in the study by Kang et al. (2017), we do not adjust the policy uncertainty shock. An increase of policy uncertainty index means more unpredicted policy changes, which would have a negative impact on the whole economy and almost all economic actors.

Figure 2 depicts the responses of real clean energy stock returns, which differ substantially depending on the four hypotheses of underlying causes in "Hypotheses" section. The first subfigure confirms the hypothesis 1 , showing the effect of unanticipated oil supply disruption on the real stock returns of the clean energy industry is transient and has a marginal statistically significant negative effect in the second month. It then becomes positively sustained in the months 6 to 19 based on one-standard error bands. In the second subfigure, the responses of the stock returns to unpredicted oil-specific demand shocks, reflected the hypothesis 3 about oil precautionary demand, are negative and statistically significant months $3-11$. For the hypothesis 4, An unanticipated economic policy uncertainty shock causes sustained and significant negative real stock returns with a lag over 8-24 months, in the third subfigure. In contrast, an unexpected aggregate demand shock causes episodical and significantly positive effects on the stock returns over months 3-6 and 10-20, in the fourth subfigure to supported the hypothesis 2. These results show that return responses of clean energy companies are, on average, delayed in the first few months, and the considered factors show their impacts are consistent with the hypotheses.

The forecast-error-variance decomposition in Panel A of Table 1 explains how important the driving factors are to US stock returns quantitatively in different forecast horizons. In the short-term, the oil-specific demand shocks account for $4.9 \%$ of the variation in the clean energy industry, whereas others are negligible (less than 1\%). Their explanatory power, however, increases as the horizon is lengthened. In the long-term, 59\% of the variation in clean energy stocks can be accounted for by oil and uncertainty shocks, more than three-fourths of which is associated with the shocks in the crude oil market. Specifically, oil supply shocks explain $14 \%$ of the variation in the US real stock return of clean energy industry. Having a powerful impact in the short-term, oil-specific market demand shocks are also the largest contributor to the clean energy returns in the long-term, accounting for $18 \%$ of the variability. The economic policy uncertainty shocks account for $15 \%$ and are the fundamental factor responsible for the variability of clean energy stock returns. The aggregate demand shocks can explain $11 \%$ of the variation, on 
Table 1 Percent contribution of shocks in the crude oil market and uncertainty to the overall variability of clean energy stock returns

\begin{tabular}{|c|c|c|c|c|c|}
\hline Horizon & Oil supply shock & $\begin{array}{l}\text { Oil-specific } \\
\text { demand shock }\end{array}$ & Uncertainty shock & $\begin{array}{l}\text { Aggregated } \\
\text { demand shock }\end{array}$ & $\begin{array}{l}\text { Clean } \\
\text { energy } \\
\text { shocks }\end{array}$ \\
\hline \multicolumn{6}{|c|}{ Panels A. Policy Uncertainty } \\
\hline 1 & 0.0020 & 4.9049 & 0.0001 & 0.9884 & 94.1046 \\
\hline 3 & 2.1684 & 7.3321 & 1.3698 & 2.3294 & 86.8004 \\
\hline 12 & 9.4949 & 16.8234 & 12.4658 & 6.1415 & 55.0743 \\
\hline 24 & 14.0741 & 16.8633 & 14.4559 & 8.0485 & 46.5581 \\
\hline 60 & 14.5422 & 18.0255 & 15.0696 & 11.2935 & 41.0692 \\
\hline \multicolumn{6}{|c|}{ Panels B. Policy Uncertainty—News coverage } \\
\hline 1 & 0.0255 & 3.4635 & 0.0288 & 0.9817 & 95.5006 \\
\hline 3 & 1.2694 & 5.8991 & 0.4147 & 2.3163 & 90.1005 \\
\hline 12 & 8.8844 & 17.6646 & 10.4524 & 5.7497 & 57.2490 \\
\hline 24 & 13.8223 & 17.1484 & 11.3199 & 8.5460 & 49.1633 \\
\hline 60 & 14.0731 & 17.5457 & 12.0978 & 12.9726 & 43.3108 \\
\hline \multicolumn{6}{|c|}{ Panels C. Policy Uncertainty - the federal/state/local purchases disagreement measure } \\
\hline 1 & 2.0578 & 5.0070 & 2.6246 & 0.0461 & 90.2645 \\
\hline 3 & 8.8775 & 8.9108 & 2.6202 & 5.4471 & 74.1443 \\
\hline 12 & 10.6530 & 19.1127 & 5.6464 & 8.1054 & 56.4825 \\
\hline 24 & 13.6915 & 18.6774 & 9.9386 & 11.0289 & 46.6636 \\
\hline 60 & 15.7700 & 18.9833 & 11.3337 & 13.7039 & 40.2091 \\
\hline \multicolumn{6}{|c|}{ Panels D. Policy Uncertainty — the CPI forecast disagreement measure } \\
\hline 1 & 5.8820 & 4.4537 & 0.3148 & 1.0939 & 88.2556 \\
\hline 3 & 14.7085 & 4.9218 & 5.9707 & 8.1116 & 66.2873 \\
\hline 12 & 17.2047 & 19.2427 & 13.5727 & 10.6852 & 39.2948 \\
\hline 24 & 20.3918 & 18.8068 & 14.0385 & 14.1066 & 32.6562 \\
\hline 60 & 21.9406 & 19.6839 & 13.4504 & 16.5778 & 28.3473 \\
\hline \multicolumn{6}{|c|}{ Panels E. Policy Uncertainty - the tax expirations index } \\
\hline 1 & 0.6951 & 3.3805 & 0.0045 & 0.9095 & 95.0104 \\
\hline 3 & 9.2458 & 6.2880 & 0.3777 & 1.6516 & 82.4369 \\
\hline 12 & 14.0176 & 12.7905 & 2.5774 & 6.9051 & 63.7095 \\
\hline 24 & 14.8854 & 14.662 & 8.6815 & 8.4580 & 53.3131 \\
\hline 60 & 17.5761 & 15.0003 & 9.1604 & 10.7726 & 47.4904 \\
\hline
\end{tabular}

Percent contributions of demand and supply shocks in the crude oil market and policy uncertainty component to the overall variability of real stock returns of renewable energy stock index. The forecast error variance decomposition is based on the structural VAR model described in the text

average, after 60 months. The rest of the variation in the return of clean energy stocks (accounting for more than $41 \%$ ) is attributed to other shocks affecting this market.

\subsection{Comparison of clean energy returns with oil and gas stock returns}

To compare the results between clean energy companies and fossil fuel companies, we also replaced the returns of the clean energy stock index with the oil and gas stock returns. ${ }^{2}$ The impulse response functions of oil and gas stock returns to structural shocks are reported in Fig. 3. The oil-specific market demand shock causes a significant and immediate increase in oil and gas returns in the first seven months, and then

\footnotetext{
${ }^{2}$ We replaced the fifth variable of $y_{t}^{\prime}$ in Eq. (1) with $\Delta \circ g_{t}$.
} 

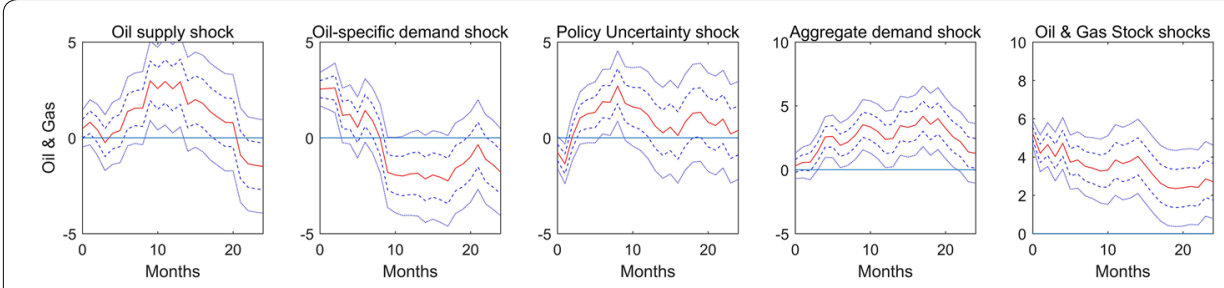

Fig. 3 Responses of oil and gas industry returns to one and two standard deviation structural shocks: 2001:01-2018:12. Notes: The figure shows the impulse response functions to one and two standard deviation structural shock, the order of SVAR model is oil supply shocks, aggregated demand shocks, oil specific demand shocks, economic policy uncertainty index and the real stock returns of the oil and gas industry described in the text. Point estimates are reported with one- and two-standard error bands constructed using a recursive-design wild bootstrap
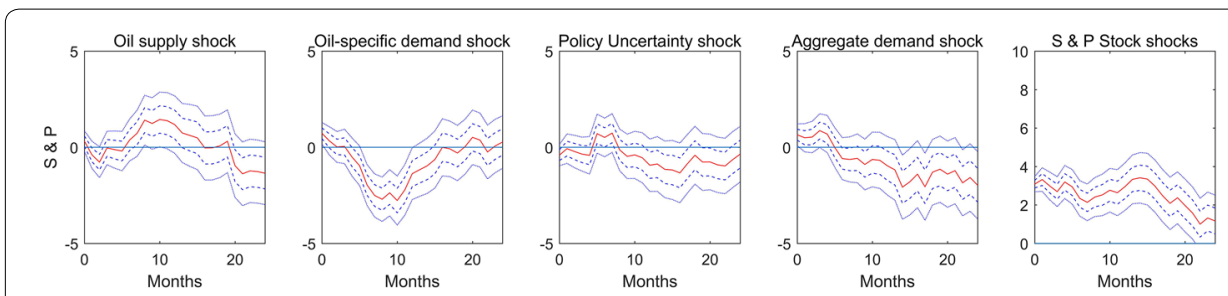

Fig. 4 Responses of S\&P 500 stock returns to one and two standard deviation structural shocks: 2001:012018:12. Notes: The figure shows the impulse response functions to one and two standard deviation structural shock, the order of SVAR model is oil supply shocks, aggregated demand shocks, oil specific demand shocks, economic policy uncertainty index and the real stock returns of the S\&P 500 stock index described in the text. Point estimates are reported with one- and two-standard error bands constructed using a recursive-design wild bootstrap

has a negative impact between months 9 to 19. Compared with the results of clean energy stocks, this dissimilarity in effect is expected. An oil-specific market demand shock represents a positive innovation for oil and gas companies due to the concern of oil users to increase the oil demand. Conversely, the returns of oil and gas companies tend to decrease due to the sharp demand increases that raise their inventories and thus decrease the demand in the future. Policy uncertainty affects the oil and gas companies through a quick decrease and becomes positive in a 1-year period after the first 3 months. The positive effect of aggregate demand shocks on oil and gas returns is more persistent than it is on clean energy industry returns, keeping an immediate and sustained increase from months 2 to 24 . Unanticipated oil production shocks have a significant positive impact in the middle months for both oil and renewable energy returns. Meanwhile, there is a significantly negative effect on the oil and gas returns at the end of 2 years, and on the clean energy returns is in the second month.

\subsection{Comparison of clean energy returns with stock market returns}

In this subsection, we compare the energy-related companies with the whole stock market and we also investigate the real stock return responses of S\&P 500 to the structural shocks represent the reactions of the overall stock market. ${ }^{3}$ Figure 4 presents the real

\footnotetext{
${ }^{3}$ We replaced the fifth variable of $y_{t}^{\prime}$ in Eq. (1) with $\Delta s p_{t}$.
} 

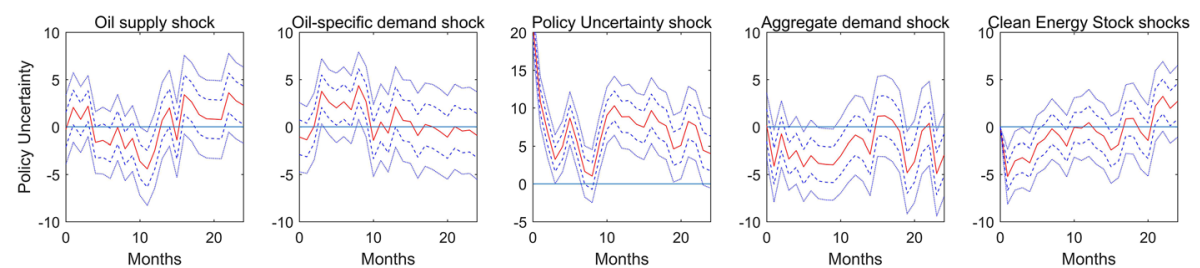

Fig. 5 Responses of policy uncertainty to one and two standard deviation structural shocks: 2001:012018:12. Notes: The figure shows the impulse response functions to one and two standard deviation structural shock, the order of SVAR model is oil supply shocks, aggregated demand shocks, oil specific demand shocks, economic policy uncertainty index and the real stock returns of the clean industry described in the text. Point estimates are reported with one- and two-standard error bands constructed using a recursive-design wild bootstrap

stock returns of S\&P 500 responses to a structural shock for each driven factor. The response of the whole stock market is relatively weaker than energy-related stocks. When there are oil supply and specific demand shocks, the return responses of the stock market in Fig. 4 have results similar to the return responses in Figs. 2, 3. However, the magnitude of the return responses to policy uncertainty is relatively smaller, which is significantly positive in months 3 to 5 and negative in months 13 to 17 and 19 to 23 . For the aggregated demand shocks, unlike the positive impacts on the energy segments over most of the time horizon, they affect the overall stock return positively in first four months, and then have a negative impact in the second year. These results are intuitive, showing that energy-related companies co-vary with the oil price fluctuations and economic policy uncertainty more closely than the aggregated stock index including the companies that are not sensitive to the energy and policy innovations.

\subsection{The role of economic policy uncertainty responses}

This subsection elaborates on the role of the endogenous economic policy uncertainty in the transmission of the three structural changes in oil price to the US real stock returns of clean energy companies. The impulse responses of policy uncertainty displayed in Fig. 5 indicate the timing and magnitude of policy uncertainty affected by other shocks. More specifically, an unanticipated oil production disruption provokes a significantly negative effect on the economic policy uncertainty in months 9 through 12 . The response of the policy uncertainty is significantly positive for unpredicted oil-market specific demand shocks between 3 and 9 months. On average, aggregate demand shocks cause a negative effect on policy uncertainty, which is statistically significant over 3 and 11 months and significantly intermittent after the 19th month.

In Fig. 6, the historical decomposition of the effect of the three structural oil price shocks on policy uncertainty displays how the oil shocks have contributed to economic policy uncertainty over time. The observed changes in the economic policy uncertainty can be explained by from a historical perspective. The contribution of oil supply to policy uncertainty is relatively weak, around zero. From the demand side, shocks from global aggregate demand and the oil-market specific demand have more influence on economic policy uncertainty with some short-period wings. It confirms that, historically, policy uncertainty has been affected by oil structural shocks (especially shocks from the demand side) in the crude oil market. 


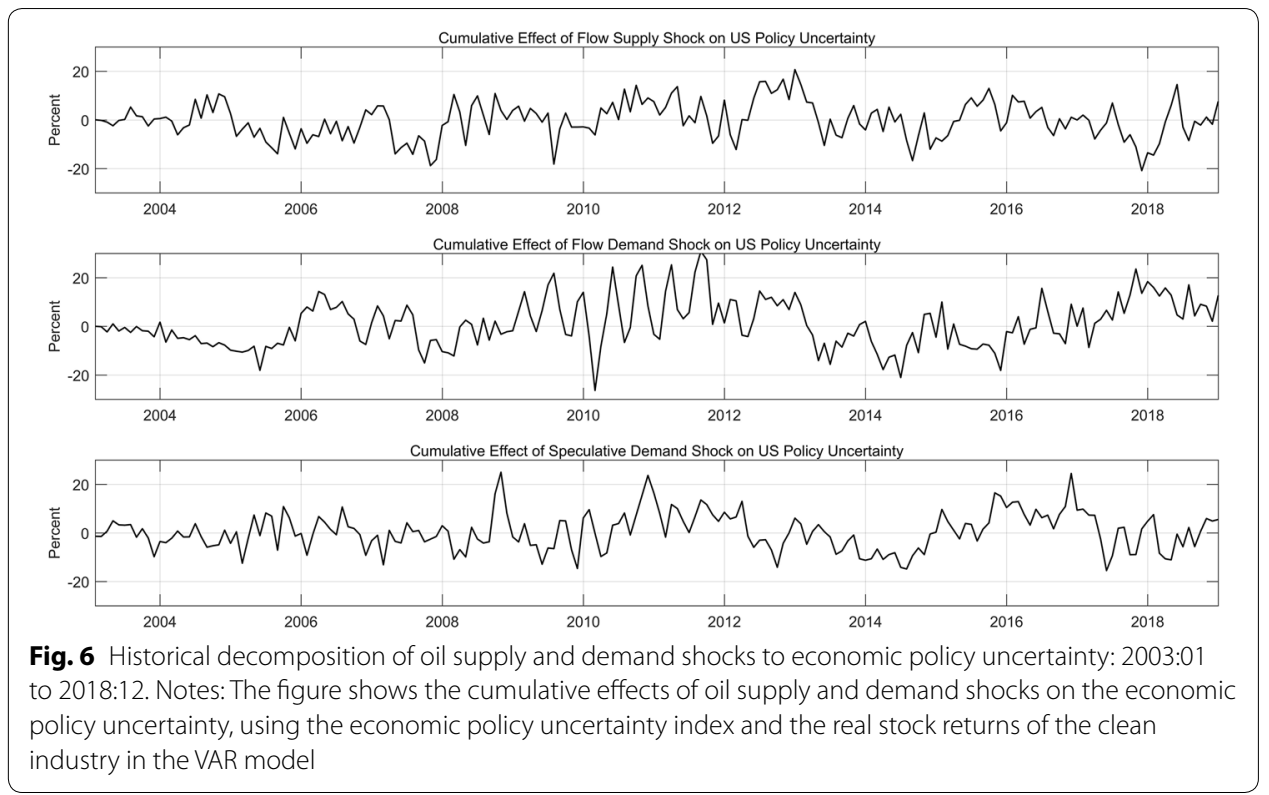

\subsection{The transmission channel of policy uncertainty}

The economic policy uncertainty index consists of four underlying components with a weighted average. The first uncertainty source is measured by the news coverage volume of some specific words that represent the uncertainty from social media. Then the disagreement levels of government purchase forecast and the CPI forecast among economic forecasters are used as the proxies for government purchase and inflation uncertainty. The fourth uncertainty component is the tax code expiration, reflecting the number of federal tax code provisions set to expire in future years (see Fig. 7).

Separating the four policy uncertainty components, we investigate the transmission channel through which policy uncertainty affects the stock returns of renewable energy companies. Figure 7 shows that the magnitude of return responses is relatively larger when there is CPI forecaster disagreement and tax code expiration uncertainties. The negative return responses to news coverage shocks and government purchase forecast disagreement are also significant over most of the forecast horizons. ${ }^{4}$ In the long run, historical decomposition shows that the shocks caused by news coverage and by the CPI forecaster disagreement account for $12.10 \%$ and $13.45 \%$ of the variation in the real stock returns of the clean energy industry, on average after 60 months (see Panel b-e of Table 1). These results imply that clean energy companies are more sensitive to information that reflects uncertainty in the inflation.

\footnotetext{
${ }^{4}$ It is worthy to mention that using these uncertainty components, the impact of aggregated demand shock become weak and oil supply shock turns to negative. We believe that it caused by the difference of transmission channels. Because all these uncertainty sources are affecting the decisions of oil and renewable energy investors and decision makers. When analyzing the impact of oil shocks, the results are more precise with the overall uncertainty.
} 


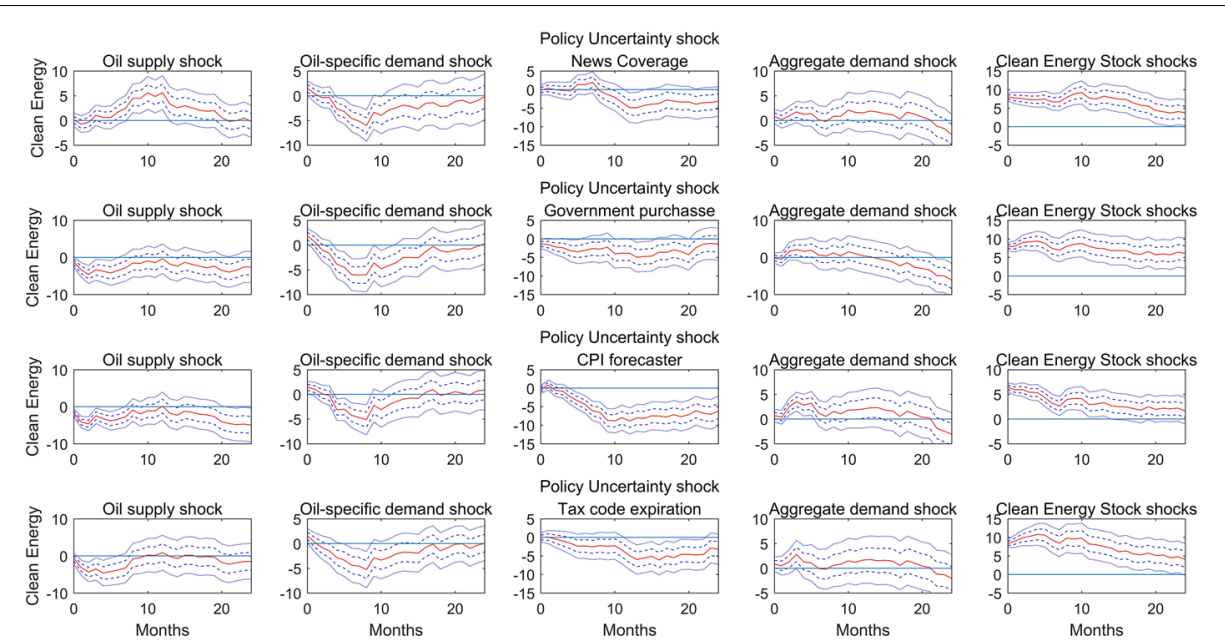

Fig. 7 Responses of clean energy industry returns to one and two standard deviation structural shocks using policy uncertainty components as policy shocks: 2001:01-2018:12. Notes: The figure shows the impulse response functions to one and two standard deviation structural shock, the order of SVAR model is oil supply shocks, aggregated demand shocks, oil specific demand shocks, economic policy uncertainty components and the real stock returns of the clean industry described in the text. The policy uncertainty data is separated according to its four components. Point estimates are reported with one- and two-standard error bands constructed using a recursive-design wild bootstrap

\section{Conclusion}

Previous studies have demonstrated that the impacts of different oil shocks and policy uncertainty on the US aggregated stock returns and oil and gas sector returns are qualitatively and quantitatively different (Kang and Ratti 2013; Kang et al. 2017). In the context of a rapidly-developing renewable energy industry, we followed Kilian's (2009) crude oil model to investigate the renewable energy stock market fluctuations associated with three different oil price shocks and policy uncertainty, endogenously. We found that these factors jointly accounted for more than half of the long-term variation in the US clean energy stock index. In doing so, we highlighted the importance of different oil shocks and policy uncertainty for the clean energy stock market. Our study also obtained useful information about the stock market behavior of clean energy companies and the portfolio choices of investors.

We found that the response of US real stock returns of clean energy segments to oil price changes varies substantially, depending on whether the substitution effect takes place among energy sectors. First, our results suggest that oil can affect the clean energy segment due to a substitution effect among energy alternatives through the oil supply channel. Oil supply shocks from an unpredicted decrease in oil production force oil consumers to adopt clean energy. This causes statistically significantly positive effects on the stock returns of clean energy corporations over forecasting periods of more than 1 year. In the long run, we found that oil supply shocks account for $14.54 \%$ of the variation in the stock returns of clean energy stocks. In a context of economic prosperity, the aggregated demand shock also triggers a transition from oil to clean energy. Energy users are more willing to adopt new types of energy sources when there is a positive future economic outlook. Therefore, the aggregated demand shocks have a positive effect on the 
stock returns of the clean energy sector. However, oil-specific market demand shocks show that the substitution effect between oil and clean energy is partial effect. The precautionary demand of oil is too sticky, for oil-specific consumers, to transition to clean energy even if the price of oil increases. Therefore, this kind of shocks does not increase the demand for clean energy, as indicated by a negative impact of the oil-specific demand shocks on the returns of clean energy stocks.

While Kilian (2009) only analyzed political disturbances exogenously, we also considered the impact of economic policy uncertainty endogenously and exhaustively. The endogenous economic policy uncertainty in the transmission of the three structural oil prices is important to the US real stock returns of clean energy companies. This is because the direct effects of oil supply and demand shocks on the stock returns of clean energy companies are amplified by the endogenous policy uncertainty responses. Through a comprehensive analysis of the policy uncertainty transmission channels, we found that the news coverage shocks and the CPI forecaster disagreement shocks account for $12.10 \%$ and $13.45 \%$ of the variation in the real stock returns of the clean energy sector in the long run.

Acknowledgements

Any errors or omissions are the fault of the authors. Thank editor and anonymous referees for the useful comments.

Authors' contributions

I wrote the entire manuscript, and takes sole responsibility for my views. The author read and approved the final manuscript.

\section{Funding}

The author is sponsored by the China Scholarship Council (CSC201706490007). Therefore, I would like to thank China Scholarship Council to give me the support.

Availability of data and materials

The data sources of all data analyzed during this study are introduced in "Data description" section.

Competing interests

I declare no potential competing interests.

Received: 28 January 2020 Revised: 8 May 2020 Accepted: 25 August 2020

Published online: 09 September 2020

\section{References}

Aloui R, Gupta R, Miller SM (2016) Uncertainty and crude oil returns. Energy Econ 55:92-100. https://doi.org/10.1016/j. eneco.2016.01.012

Antonakakis N, Chatziantoniou I, Filis G (2013) Dynamic co-movements of stock market returns, implied volatility and policy uncertainty. Econ Lett 120(1):87-92. https://doi.org/10.1016/j.econlet.2013.04.004

Antonakakis N, Chatziantoniou I, Filis G (2014) Dynamic spillovers of oil price shocks and economic policy uncertainty. Energy Econ 44:433-447. https://doi.org/10.1016/j.eneco.2014.05.007

Baker SR, Bloom N, Davis SJ (2016) Measuring economic policy uncertainty. Q J Econ 131(4):1593-1636. https://doi. org/10.1093/qje/qjw024

Bondia R, Ghosh S, Kanjilal K (2016) International crude oil prices and the stock prices of clean energy and technology companies: evidence from non-linear cointegration tests with unknown structural breaks. Energy 101:558-565. https://doi.org/10.1016/j.energy.2016.02.031

Degiannakis S, Filis G, Panagiotakopoulou S (2018) Oil price shocks and uncertainty: How stable is their relationship over time? Econ Model. https://doi.org/10.1016/j.econmod.2018.01.004

Dutta A (2017) Oil price uncertainty and clean energy stock returns: New evidence from crude oil volatility index. J Clean Prod 164:1157-1166

Dutta A, Bouri E, Noor MH (2018) Return and volatility linkages between $\mathrm{CO}_{2}$ emission and clean energy stock prices. Energy 164:803-810. https://doi.org/10.1016/j.energy.2018.09.055

Ferrer R, Shahzad SJH, López R, Jareño F (2018) Time and frequency dynamics of connectedness between renewable energy stocks and crude oil prices. Energy Econ 76:1-20. https://doi.org/10.1016/j.eneco.2018.09.022

Gonçalves SL, Kilian L (2004) Bootstrapping autoregressions with conditional heteroskedasticity of unknown form. J Econ 123(1):89-120. https://doi.org/10.1016/j.jeconom.2003.10.030

Henriques I, Sadorsky P (2008) Oil prices and the stock prices of alternative energy companies. Energy Economics 30(3):998-1010. https://doi.org/10.1016/j.eneco.2007.11.001 
Inchauspe J, Ripple RD, Trück S (2015) The dynamics of returns on renewable energy companies: a state-space approach. Energy Econ 48:325-335. https://doi.org/10.1016/j.eneco.2014.11.013

Ji Q, Liu B-Y, Nehler H, Uddin GS (2018) Uncertainties and extreme risk spillover in the energy markets: a time-varying copula-based CoVaR approach. Energy Econ 76:115-126. https://doi.org/10.1016/j.eneco.2018.10.010

Kang W, Perez de Gracia F, Ratti RA (2017) Oil price shocks, policy uncertainty, and stock returns of oil and gas corporations. J Int Money Fin 70:344-359. https://doi.org/10.1016/j.jimonfin.2016.10.003

Kang W, Ratti RA (2013) Structural oil price shocks and policy uncertainty. Econ Model 35:314-319. https://doi. org/10.1016/j.econmod.2013.07.025

Kilian L (2009) Not all oil price shocks are alike: disentangling demand and supply shocks in the crude oil market. Am Econ Rev 99(3):1053-1069. https://doi.org/10.1257/aer.99.3.1053

Kilian L, Park C (2009) The impact of oil price shocks on the US stock market*. Int Econ Rev 50(4):1267-1287. https://doi. org/10.1111/j.1468-2354.2009.00568.x

Kilian L, Vega C (2011) Do energy prices respond to US macroeconomic news? A test of the hypothesis of predetermined energy prices. Rev Econ Stat 93(2):660-671. https://doi.org/10.1162/REST_a_00086

Kim G, Vera D (2018) Recent drivers of the real oil price: revisiting and extending Kilian's (2009) findings. Energy Econ. https://doi.org/10.1016/j.eneco.2017.12.020

Kumar S, Managi S, Matsuda A (2012) Stock prices of clean energy firms, oil and carbon markets: a vector autoregressive analysis. Energy Econ 34(1):215-226. https://doi.org/10.1016/j.eneco.2011.03.002

Liu L, Zhang T (2015) Economic policy uncertainty and stock market volatility. Fin Res Lett 15:99-105. https://doi. org/10.1016/j.frl.2015.08.009

Lundgren Al, Milicevic A, Uddin GS, Kang SH (2018) Connectedness network and dependence structure mechanism in green investments. Energy Econ 72:145-153. https://doi.org/10.1016/j.eneco.2018.04.015

Managi S, Okimoto T (2013) Does the price of oil interact with clean energy prices in the stock market? Jpn World Econ 27:1-9. https://doi.org/10.1016/j.japwor.2013.03.003

Paiva ASS, Rivera-Castro MA, Andrade RFS (2018) DCCA analysis of renewable and conventional energy prices. Phys A 490:1408-1414. https://doi.org/10.1016/.jphysa.2017.08.052

Reboredo JC (2015) Is there dependence and systemic risk between oil and renewable energy stock prices? Energy Econ 48:32-45. https://doi.org/10.1016/j.eneco.2014.12.009

Reboredo JC, Rivera-Castro MA, Ugolini A (2017) Wavelet-based test of co-movement and causality between oil and renewable energy stock prices. Energy Econ 61:241-252. https://doi.org/10.1016/j.eneco.2016.10.015

Reboredo JC, Ugolini A (2018) The impact of energy prices on clean energy stock prices. A multivariate quantile dependence approach. Energy Econ 76:136-152. https://doi.org/10.1016/j.eneco.2018.10.012

Sadorsky P (2012) Correlations and volatility spillovers between oil prices and the stock prices of clean energy and technology companies. Energy Econ 34(1):248-255. https://doi.org/10.1016/j.eneco.2011.03.006

\section{Publisher's Note}

Springer Nature remains neutral with regard to jurisdictional claims in published maps and institutional affiliations.

\section{Submit your manuscript to a SpringerOpen ${ }^{\circ}$ journal and benefit from:}

- Convenient online submission

- Rigorous peer review

- Open access: articles freely available online

- High visibility within the field

- Retaining the copyright to your article

Submit your next manuscript at $\mathbf{s p r i n g e r o p e n . c o m ~}$ 